\title{
FLORA DA SERRA DO CIPÓ, MINAS GERAIS: CAMPANULACEAE ${ }^{(1)}$
}

\author{
SILVANA APARECIDA PIRES DE GODOY
}

Instituto de Biociências, Universidade de São Paulo, CP 11461 - 05422-970 - São Paulo, SP, Brasil. Bolsista do CNPq.

\begin{abstract}
Flora of the Serra do Cipó, Minas Gerais : Campanulaceae). The study of the family Campanulaceae is part of the project of "Flora of Serra do Cipó, Minas Gerais, Brasil". In that area, the family is represented by the three genera : Wahlenbergia Schrad. with one species, W. brasiliensis Cham.; Siphocampylus Pohl, with three species, S. nitiduss Pohl, S. sulfureus E. Wimm and S. westinianus (Billb.) Pohl; and Lobelia L. with three species too, L camporum L., L. fistulosa Vell. and $L$ organensis Gardn. ssp. organensis. Keys to the genera and species, descriptions and illustrations, as well as comments on the geographic distribution and morphological variation of the species are presented.
\end{abstract}

RESUMO - (Flora da Serra do Cipó, Minas Gerais : Campanulaceae). O estudo da familia Campanulaceae é parte do levantamento da Flora da Serra do Cipó, Minas Gerais, Brasil. Esta família está representada naquela área por três gêneros: Wahlenbergia Schrad. com uma espécie, W. brasiliensis Cham; Siphocampylus Pohl, com três espécies, S. nitidus Pohl. S. sulfureus E. Wimm. e S. westinianus (Billb.) Pohl e Lobelia L. também com três espécies, $L$ comporum $L$., $L$ fistulosa Vell. e $L$ organensis Gardn ssp. organensis. Sāo apresentadas chaves para a identịficação dos gêneros e espécies, descrições e ilustraçōes das mesmas, além de comentários sobre sua distribuição geográfica e variação morfológica.

Key words: Campanulaceae, Serra do Cipó floristics, campo rupestre vegetation.

\section{CAMPANULACEAE}

Ervas, subarbustos, menios freqüentes arbustos $\theta$ arvoretas. Substância de reserva inulina, poliacetilenos presentes e, em algumas Lobelioideae; alcalóides piridínicos; ausentes compostos iridöides e proantocianidinas, raro compostos cianogênicos, saponinas, taninos e ácidos elágicos. Sistema laticifero bem desenvolvido no floema $e$ xilema, se estendendo para os tecidos circundantes, aproximando-se de tal forma que xilema e floema tornam-se um cilindro contínuo. Folhas simples, alternas, raro opostas ou verticiladas, sem estípulas, estômatos anomocíticos. Inflorescência variada, apresentando transição de racemosa a cimosa; flores perfeitas ou raramente unissexuadas, freqüentemente (3-5-10-) mera, epiginas, menos freqüente flor perígina ou hipógina; corola campanulada ou tubulosa, podendo entāo ser ressupinada, bilabiada, sendo os lobos iguais ou desiguais entre si, de pré-floração valvar; cálice unido ao ovário, formando o hipanto, com cinco dentes ou lobos; estames em número de cinco, alternos aos lobos da corola; filetes unidos em um tubo ou livres entre si, sempre aderidos ao disco nectarifero ou à base da corola, sendo disjunto (Campanuloideae) ou unidos ao tubo da corola pouco acima da base (Lobelioideae); anteras livres entre si ou unidas em tubo, introrsas; gineceu dois a cinco carpelos unidos (três em Campanuloideae e dois em Lobelioideae), ovário infero ou ocasionalmente semi-infero, raro súpe-

(1) Trabalho feito dentro do planejamento apresentado por Giulietti et al. (1987). Parte da Dissertação de Mestrado apresentada ao Depto. de Botânica do Instituto de Biociências, USP, sob a orientação de A. Salatino. 
ro (Cyananthus), igual número de lóculos e carpelos, mas, em algumas Lobelioideae, uniloculares com duas placentas parietais $\theta$, em algumas Campanuloideae, os lóculos primários se dividem em lóculos menores pela intrusāo de tecidos dos carpelos; estilete terminal, estigma seco ou úmido, igual número de lobos do estigma e carpelos; Óvulos muitos, placentação axilar (raro parietal), anátropos, tenuinucelados, endosperma celular, com haustório terminal. Fruto cápsula, poricida ou aberto por valvas apicais, que podem ser em número maior que o de carpelos, menos freqüente o tipo baga; sementes muitas, pequenas, podendo ser aladas.

Bibliografia básica - Barroso of al. (1986), Cronquist (1981), Thulin (1975), Wimmer (1957).

\section{Chave para os gêneros}

1. Flores actinomorfas, inflorescência paniculada, corola campanulada, anteras e filetes livres.... 1. Wahlenbergia

1 ' Flores zigomorias, solitárias ou em racemos, corola tubulosa, anteras unidas, filetes totalmente unidos ou disjuntos próximo à base.

2. Tubo da corola inteiro. 2. Siphocampylus

2 ' Tubo da corola longitudinalmente fendido na regiāo anterior 3. Lobelia

\section{Wahlenbergia Schrad.}

Wahlenbergia brasiliensis Cham., Linnaea 8: 318.1833.

Figs. 1-10

Ervas $0,30-0,70 \mathrm{~m}$ alt., glabras ou pouco pubescentes, eretas, rizomatosas. Caule cilíndrico, estriado. Folhas alternas, adpressas, eretas, estreito-lanceoladas a subuladas, $0,3-0,6 \mathrm{~cm}$ compr., 0,04-0,08 cm larg. na base ; margem inteira, ápice subobtuso. Inflorescência paniculada, eixo dicotômico, freqüentemente glabro, raro com tricomas esparsos, com poucas flores; brácteas semelhantes às folhas, $0,15-0,3 \mathrm{~cm}$ compr.; pedicelo $0,3-1,0 \mathrm{~cm}$ compr., bibracteolado, glabro; flores azuis ou violáceas até esmaecidas; corola $0,4-0,8 \mathrm{~cm}$, campanulada, glabra, com tubo distinto e lobos de dimensões equivalentes à metade das dimensōes da corola. Hipanto $0,1-0,3 \mathrm{~cm}$ compr., 0,1 - 0,3 cm larg., turbinado, agudo, glabro, 10-nervado; lobos 0,2 - 0,35 cm compr., lanceolados, inteiros, eretos, glabérrimos; filetes livres, ampliados próximo à base, ciliados; ovário infero, trilocular, com muitos óvulos de placentação axilar, estilete cilindrico, oco, regiāo inferior glabra $\theta$ superior coberta por tricomas coletores de pólen; estigma trilobado. Cápsula cilindrica, alongada, loculicida com 3 valvas, 0,25 - 0,4 cm compr., 0,15-0,45 cm larg.; sementes muitas, pequenas, ovóides.

Material selecionado. Santana do Riacho, Serra do Cipó, Rodovia Belo Horizonte-Conceição do Mato Dentro: km 106, CFSC 9850, col. S.A.P. Godoy, N.S. Chukr, P.U. Ávila, 26.VII.1986, (SPF); km 110, CFSC 8771; col. E. Forero et al. 7858, 06.IX.1980 (SPF); km 116, CFSC 1189, col. A.B. Joly. J. Semir \& Y. Ugadim, 07.VI.1970 (UEC); km 120, CFSC 9337, col. D.C. Zappi,

Figs. 1-10 - Wahlenbergia brasiliensis Cham. 1 - Hábito, 2 - Folha, lace abaxial, 3 - Folha, em vista lateral, 4 Ramo com botōes fiorais, 5 - Flor, 6 - Flor aberta, mostrando a disposição dos estames, 7 - Estame, 8 Gineceu, com ovário em corte longitudinal, 9 - Ovário, corte transversal, 10 - Semente.

Figs. 1-10 - Wahlenbergia brasiliensis Cham. 1 - Habit, 2 - Leaf, abaxial face, 3 - Leaf, lateral view, 4 - Shoot with floral bud, 5 - Flower, 6 -Open flower, showing the arrangement of stamens, 7 - Stamen, 8 - Gynoecium,
longitudinal section of ovary, 9 - Ovary, transversal section, 10 - Seed. 


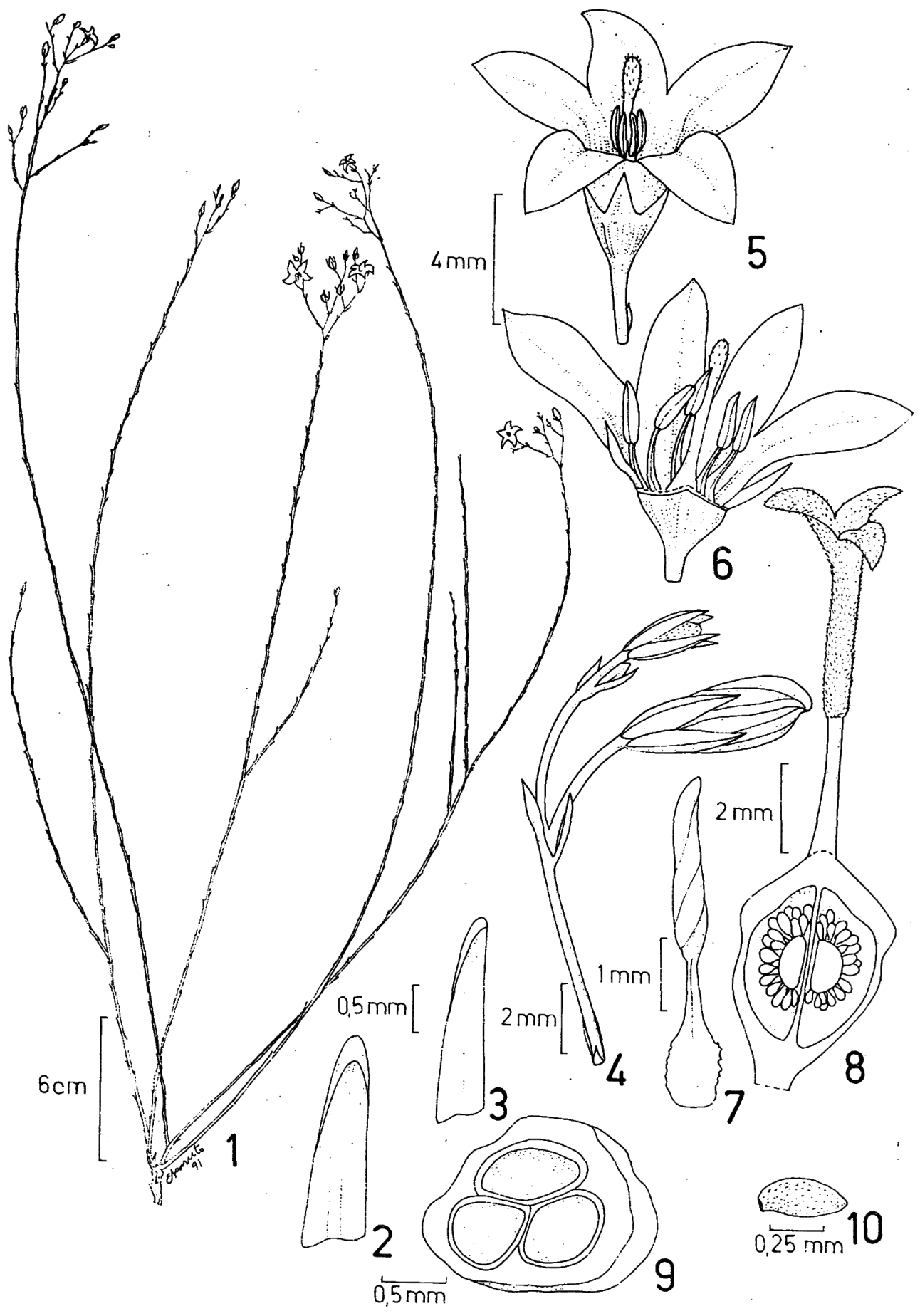


19.VII.1985 (SPF); km 121, CFSC 7345, col. A.M. Giulietti ot al., 30.VI.1981 (SPF); km 125, CFSC 10349, col. S.A.P. Godoy ot al., 22.VII.1987 (SPF); km 125, CFSC 11163, col. S.A.P. Godoy et al., 25.VI.1988 (SPF); km 126, CFSC 9843, col. S.A.P. Godoy, N.S. Chukr \& P.U. Ávila, 25.VIl.1986 (SPF); km 127, CFSC 11161, col. S.A.P. Godoy et al., 25.VI.1988 (SPF); km 128, CFSC 6445, col. A. Furlan, I. Cordeiro \& J.R. Pirani, 23.VIII.1980 (SPF); km 132, col. Mello Barreto, 98641 (R), 02.1X.1933; km 134, CFSC 6400, col. N.L. Menezes et al., 23.VI.1980 (SPF); km 136, CFSC 1185, col. A.B. Joly \& J. Semir, 22.VIII.1972 (UEC); km 139, CFSC 1188, col. A.B. Joly \& J. Semir, 22.Vill.1972 (UEC); km 140, col. A.B. Joly \& C. Müller, 10.IX.1972 (SP 145743).

Espécie do Brasil, bem distribuída nos estados de Minas Gerais e São Paulo, ocupa desde campos rupestres até brejos, geralmente em locais de altitude. Pode ser encontrada também em barrancos à beira de estradas, em terrenos em transição de vegetação $\theta$ que sofreram ação antrópica. A maior concentração de plantas em flor é de junho a setembro, com ápice de floração em jutho.

W. brasiliensis Cham. não apresenta grande variação morfológica, podendo-se ressaltar a distribuição differenciada de folhas, que em alguns espécimes é mais densa, ficando muito próximas umas das outras, por vezes com disposição quase espiralada no ramo, principalmente próximo à inflorescência. Podem variar também em relação ao indumento, que pode estar ausentê em alguns espécimes, enquanto em outros os tricomas estão dispersos no ramo, dando ao mesmo o aspecto escabro.

A cor da corola varia de azul profundo a lilás, apresentando-se às vezes esmaecida, o que pode ser atribuído às condiçōes do ambiente ou estágio de desenvolvimento da flor.

W. brasiliensis assemelha-se pouco a outra espécie do gênero que ocorre no Brasil, $W$. linarioides (Lam.) A.DC. (Kanitz 1885), sendo distinta desta pelo formato e tamanho das folhas, hipanto menos alongado e estigma trilobado. Parece que nāo coexistem na mesma área, sendo a segunda espécie característica dos estados mais ao Sul como Paraná, Santa Catarina e Rio Grande do Sul e apresentando época de floração distinta, pois enquanto $W$. brasiliensistem pico de floração nos meses de julho-agosto, $W$. linarioides floresce especialmente nos meses de janeiro-fevereiro.

\section{Siphocampylus Pohi}

Arbustos ou subarbustos, eretos, procumbentes ou escandentes, pouco ramificados. Folhas alternas ou verticiladas, raro tendendo a opostas; margem inteira, denteada, serreada ou crenada, com dentículos adpressos ou não, de ápice proeminente; sésseis ou pecioladas. Flores isoladas, axilares, podendo condensar-se no ápice do ramo, assemelhando-se a um racemo, ou reunidas em inflorescências terminais racemosas ou corimbóides; corola vermelha, violácea, amarela ou creme-esverdeada, de tubo inteiro, estreito ou largo, curvado ou ereto, geralmente constrito acima da base, formando um istmo, a partir do qual dilata-se suave ou abruptamente, abrindo-se em $5 \mathrm{lo}$ bos desiguais ou quase iguais, linear-agudos ou triangular-subfalcados, 3 superiores pouco disjuntos, deflexos ou sub-eretos, 2 inferiores deflexos. Hipanto turbinado, depresso-globoso ou hemisférico, deixando livres 5 lobos calicinos; filetes 5 , unidos em tubo, totalmente livre da corola ou unido do istmo à base, podendo estar livres entre si, glabro ou pubescente; anteras 5, ern tubo amarelo-pálido ou cinéreo, glabro ou pubescente, ápice das 2 inferiores piloso-penicilado; ovário semi-infero ou ínfero, bilocular, com muitos óvulos de placentaçāo axial; estilete filiforme, inserido no tubo estaminal, não concrescido; estigma bilobado, superticie estigmática glandulosa. Cápsula 
unida ou parcialmente livre do hipanto, deiscente por 2 valvas apicais ovais; lobos calicinos persistentes; sementes muitas, pequenas, geraimente elipsoideas.

\section{Chave para as espécies}

1. Folhas alternas

1. S. nitidus

1'Folhas verticiladas

2. Tubo da corola ereto, mais ou menos cilíndrico, lobo inferior disjunto até próximo à base....... 2. S. sulfureus

2' Tubo da corola subcurvo, constrito na base, ampliando-se para o ápice, lobos disjuntos a partir de $3 / 4$ da base 3. S. westinianus

1. Siphocampylus nitidus Pohl, PI. Brasil. Icones et Descript. 2: 110. 1831.

Figs. 17-19

Nome vulgar: bico-de-periquito (fide Tales 026, BHCB).

Subarbustos decumbentes ou escandentes, 0,60-2,0 m alt.; pubescentes, ramos inferiores glabros. Folhas eretas ou não, ovais a oval-lanceoladas, coriáceas a submembranáceas, face adaxial brihhante, glabra ou com tricomas esparsamente distribuidos; face abaxial pálida, hirta, com venaçāo finamente reticulada; distintas quanto às dimensōes em inferiores e superiores; foThas inferiores, 5,0 - 11,5 cm compr., 2,5 - 6,0 cm larg.; folhas superiores, 2,8 - 6,5 cm compr., 0,8 $3,2 \mathrm{~cm}$ larg.; margem foliar denticulada, dentículos desiguais, raro profundamente denteada; base foliar subcordada a arredondada, raro cordada; ápice agudo a acuminado, raro cuspidado. Pecioio híspido, $0,5-1,4(2,0) \mathrm{cm}$ compr. Flores isoladas, axilares, ou congestas formando subracemo; pedicelo hispido $1,2-4,5(5,5-6,0) \mathrm{cm}$ compr., bibracteolado, podendo atingir $7,0 \mathrm{~cm}$ compr. no fruto; corola 4,0 - 5,6 cm compr.; tubo vermelho-escuro ou vináceo, subcurvado, pouco ampliado do istmo à fauce, hirto; lobos amarelos externamente, internamente vermelhos ou vináceos ou ainda lobos verdes, triangulares-subfalcados, aproximadamente $1 / 4$ do comprimento da corola. Hipanto hemisférico, raro semigloboso-turbinado, híspido, , 0,2-0,5 cm compr., 0,4-0,8 cm larg.: lobos subulados, eretos a arcado-recurvados, inteiros, hirtos, $0,4-1,3 \mathrm{~cm}$ compr; tubo de filetes glabro, não ultrapassando em comprimento a corola; tubo de anteras cinéreo ou cinza-claro, glabro a levemente piloso, 2 anteras inferiores piloso-peniceladas, $0,6-0,8 \mathrm{~cm}$ compr., $0,15-0,25 \mathrm{~cm}$ larg. Cápsula, globosa, deiscente por duas valvas apicais, 0,4-0,6 cm compr., 0,8 - 1,1 larg.; sementes muitas, elíptico-alongadas, achatadas, finamente reticuladas, castanho-escuras, brilhantes, $0,8 \mathrm{~mm}$.

Material selecionado: Santana do Riacho, Serra do Cipó, Rodovia Belo Horizonte-Conceição do Mato Dentro: km 106, CFSC 10129, col. D.C. Zappi, F.A. Vitta \& T.B. Cavalcanti, 08.V.1987 (SPF); CFSC 11175, col. S.A.P. Godoy et al., 26.VI.1988 (SPF), km 107, Estrada para Usina Pacifico Mascarenhas, CFSC 8910, col. E. Forero et al. 7997, 07.IX.1980 (SPF); km 110, CFSC 10269, col. S.A.P. Godoy et al., 21.VII.1987. (SPF); km 111, CFSC 9656, col. T.B. Cavalcanti et al., 02.V.1986 (SPF); CFSC 9824, col. S.A.P. Godoy, N.S. Chukr \& P.U. Ávila, 24.VII.1986 (SPF); CFSC 9846, col. S.A.P. Godoy, N.S. Chukr \& P.U. Ávila, 26. VIl.1986 (SPF); km 118, CFSC 9664, col. T.B. Cavalcanti et al., 02.V.1986 (SPF); km 120,5, CFCS 8789, col. E. Forero, N.L. de Menezes \& S.M. Dietrich ot al. 7876, 06.VIII.1982 (SPF); km 124, CFSC 9825, col. S.A.P. Godoy, N.S. Chukr \& P.U. Ávila, 24.VII.1986 (SPF); km 128, col. Mello Barreto, 98674, 02.1X.1933 (R); km 131, col. A.P. Duarte 2052, 04.XII.1949 (RB); km 137, col. A.M. Giulietti et al., 15.VIII.1979 (SP 209377); 
km 139 (Biiurcação), CFSC 11142, col. S.A.P. Godoy et al., 25.VI.1988 (SPF); col. Mello Barreto (R 98680).

Espécie do Brasil, que parece ser endêmica da região serrana de Minas Gerais, pois não é citada para nenhum outro estado. Ocupa principaimente campos rupestres ou limpos, sendo pou. co menos freqüente em mata e rara em cerrados ou terrenos brejosos. Geralmente é umbrófila, sendo encontrada principalmente à sombra de pedras no campo rupestre. Os espécimes de mata sāo escandentes, ficando a porção superior do ramo geralmente exposta ao Sol. A maior concentração de espécimes em flor ocorre nos meses de abril a setembro, tendo como auge de floração o mês de julho.

S. nitidus Pohl apresenta ampla variação quanto à forma $\theta$ dimensōes das folhas, comprimento do pedicelo e corola. É variável também, a distribuição de tricomas, ocorrendo espécimes pubescentes ou glabrescentes. A variação poderia levar ao reconhecimento de variedades e forma, baseando-se em Wimmer (1957); contudo, a existência de formas intermediárias entre os caracteres utilizados pelo autor para distinguir as variedades, tais como formato de folhas, distribuição de indumento, estado ereto ou deflexo dos lobos do cálice e a variação destes até num mesmo espécime, dificulta enquadrar o material examinado na regiāo dentro das variedades e forma estabelecidas pelo autor.

Parece haver correlação entre o habitat $\theta$ as variações morfológicas, havendo diferenças entré os espécimes que ocupam áreas de campo rupestre, entre rochas, cerrados ou orla de matas e aqueles do interior destas, principalmente quanto ao tamanho e forma das folhas $\theta$ ao hábito, que é escandente. Assim, o que se conclui é a existência de uma maior plasticidade da espécie, forṃando populaçōes diferenciadas, que refletem na variaçäo morfológica as condiçōes ambientais, näo sendo adequado o uso de categorias infraespecíficas.

Pelo material observado, conclui-se que $S$. nitidus foi inúmeras vezes confundida com $S$. macropodus, especialmente pela disposiçāo das flores, que no ápice do ramo tornam-se congestas e pelo comprimento do pedicelo, embora tais espécies sejam muito distintas pela corola, que em S. nitidus é maior, mais ou menos ereta, hirta, com as lobos falcados e não apresentando reentrâncias muito evidentes pela uniāo dos filetes ao tubo da corola. Além disso, são distintas também pelo tamanho e cor do tubo de anteras. Quanto aos caracteres vegetativos são distintas pela forma, tamanho, textura das folhas, tipo de margem e denticulos, que em S. macropodus são membranáceas, discolores, geralmente ovais a oval-oblongas, de margem repando-denteada, raro crenulado-denticulada, com dentículos adpressos ou nāo, alvos, castanhos ou arroxeados, face abaxial vilosa $e$ adaxial com tricomas eretos, esparsamente distribuidos, base foliar atenuada, podendo ser desigual, prolongando-se pelo pecíolo em pequenina ala; são distintas ainda pelo látex de odor desagradável e característico em $S$. macropodus.

2. Siphocampylus sulfureus E. Wimm., Fedde Repert. 22: 213. 1926.

Figs. 11-13

Nome vulgar: Jaratataca (Corrêa 1984).

Figs. 11-19 - Siphocampylus: 11-13 - S. sulfureus E. Wimm., 11 - Pamo com flores, 12 - Flor em vista lateral, 13 - Semente. 14-16 - S. Westinianus (Billb.) Pohl, 14 - Ramo com flores, 15 - Flor em vista lateral, 16 Semente. 17-19 - S. nitidus Pohl, 17 - Ramo com flores, 18 - Flor em vista lateral, 19 - Semente.

Figs. 11-19-Siphocampylus : 11-13 - S. sulfureus E. Wimm., 11 - Shoot with flowers, 12 - Flower lateral view, 13-Seed. 14-16 - S. westinianus (Billb.) Pohl, 14 - Shoot with flowers, 15 - Flower, lateral view, 16 - Seed. 17-19 - S. nitidus Pohl, 17 - Shoot with flowers, 18 - Flower, lateral view, 19 - Seed. 


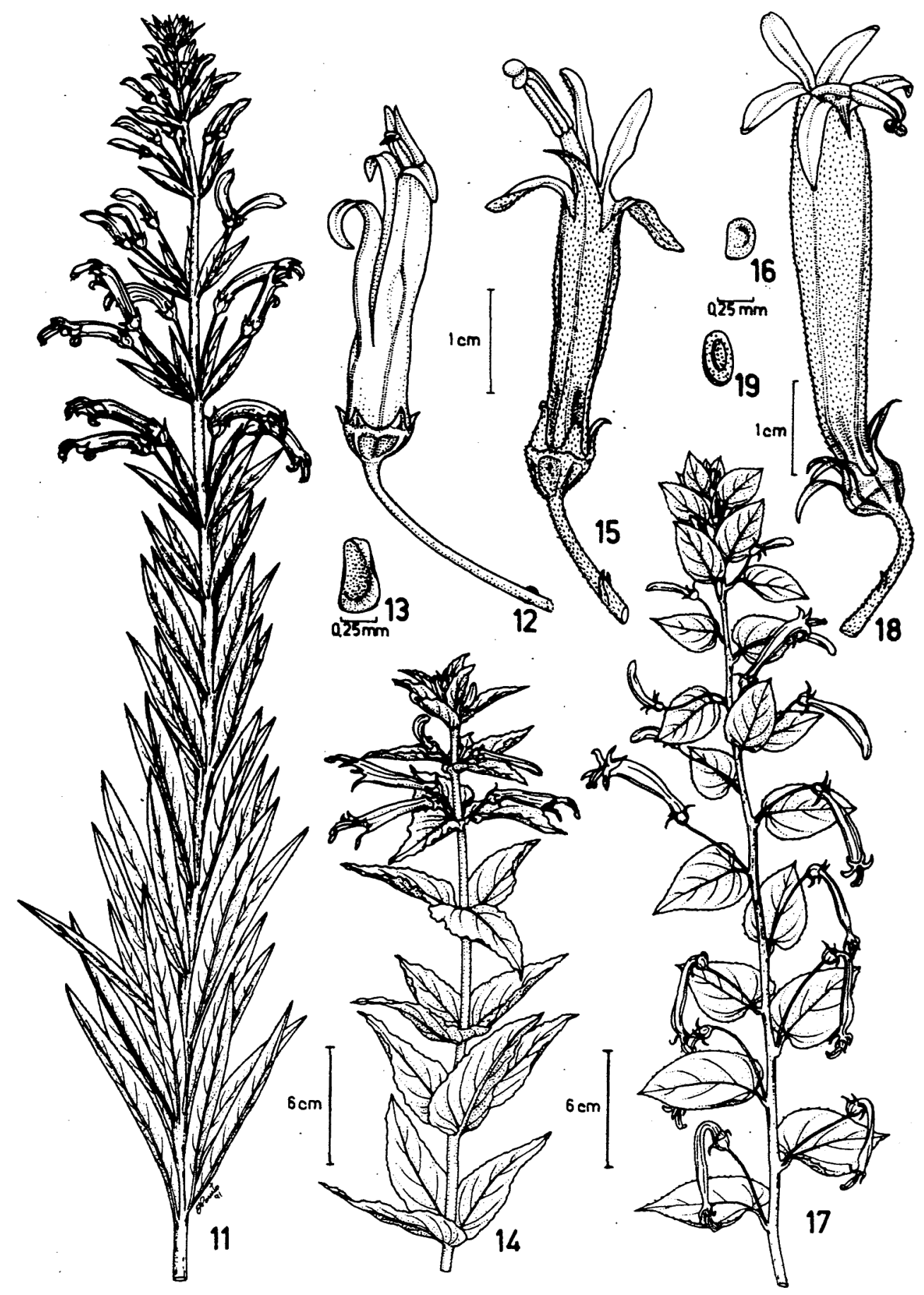


Erva robusta, ereta, glabra, 1,0 - 2,0 m alt; caule estriado, amarelo-pálido. Folhas verticiladas, sésseis, subdecurrentes, em entrenós distanciados, 4-8 por verticilo, glabras-brilhantes a levemente pubescentes; margem inteira, com dentículos minutos de ápice proeminente, raro denteada-denticulada; ápice agudo; distintas quanto à forma e dimensōes em folhas da regiāo vegetativa e da regiäo florifera: as primeiras são lanceoladas a linear-lanceoladas, $8,0-20,0 \mathrm{~cm}$ compr., $1,0-3,0 \mathrm{~cm}$ larg. $\Theta$ as segundas ovais a oval-lanceoladas até lanceoladas, $1,7-5,0 \mathrm{~cm}$ compr., 0,5 - 1,3 cm larg. . Flores verticiladas, em mesmo número que as folhas; pedicelo 2,6 - 4,5 cm compr., glabro ou pubescente, compresso, bibracteolado na base; corola $2,5-4,0 \mathrm{~cm}$ compr., tubo sulfúreo ou arnarelo-pálido, podendo apresentar-se levemente vináceo na região dorsal, reto, de mesma largura em toda a extensão, glabro, raro pubescente; lobos de ápice interna e/ou externamente vináceos, quatro lobos sublineares de igual comprimento e largura, um lobo linear disjunto até próximo à base. Hipanto amplamente turbinado, glabro, $0,5-0,9 \mathrm{~cm}$ larg., $0,2-0,5 \mathrm{~cm}$ compr.; lobos triangulares, agudos, denticulados, eretos, $0,3-0,4 \mathrm{~cm}$ compr.; tubo de filetes glabro, pouco menor que a corola; tubo de anteras cinéreo, glabro, $0,8-1,0 \mathrm{~cm}$ compr., $0,3 \mathrm{~cm}$ larg. . Cápsula ovóide, verde-arroxeada, 0,7-1,2 cm larg., 0,4-1,1 cm compr.; sementes muitas, oblongas, castanho-avermelhadas, brilhantes, circundadas por ala finamente reticulada, $0,1 \mathrm{~cm}$.

Material examinado. Santana do Riacho, Serra do Cipó, Rodovia Belo Horizonte-Conceição do Mato Dentro: km 127, CFSC 9942, col. S.A.P. Godoy \& N.S. Chukr, 15.l.1987 (SPF); CFSC 10832, col. N.L. de Menezes et al., 13.XIl.1987 (SPF); CFSC 10895, col. S.A.P. Godoy, V. Piliackas \& J.M. Piliackas, 15.Il.1988 (SPF); CFSC 10899, col. S.A.P. Godoy, J.M. Piliackas, V. Piliackas, 15.ll.1988 (SPF); km 132,5, CFSC 7168, col. M.C.E. Amaral, J.R. Pirani \& I. Cordeiro, 03.II!.1981 (SPF); km 138, CFSC 9583, col. I. Cordeiro et al., 27.l.1986 (SPF).

Siphocampylus sulfureus é espécie do Brasil, principalmente distribuida ṇos estados de Minas Gerais, Rio de Janeiro, São Paulo, Paraná, Santa Catarina e Rio Grande do Sul, ocupando brejos ou locais alagados, em regiōes serranas, acima de $1000 \mathrm{~m}$ de altitude. Erva anual, encontra-se florida nos meses de dezembro a maio, com auge em janeiro-fevereiro, época em que os terrenos mais baixos tornam-se alagados.

Na Serra do Cipó, encontrou-se populaçōes cujos espécimes melhor se enquadram em $S$. sulfureus var. glaber, que segundo Wimmer (1957), pode ser distinguida de S: sulfureus var. sulfureus por apresentar folhas linear-lanceoladas em nós muito próximos, sendo plantas totalmente glabras. Contudo, pelo material examinado, a distinção mais conclusiva entre as duas variedades é a presença do indumento. A forma das folhas é variável num mesmo espécime, apresentando transição entre as formas lanceolada e linear-lanceolada. Quanto ao tamanho do entrenó, os verticilos inferiores são sempre mais distanciados que os superiores, sendo necessário a planta inteira (o que nem sempre é possivel) para se avaliar com segurança tal caracteristica.

Os espécimes analisados variam também em relação ao número de folhas por verticilo, sendo tal variação notada até em um mesmo espécime ou em espécimes de uma mesma população. Pode-se notar também variação no tamanho da corola e pedicelo, mas tal variação está muito relacionada ao desenvolvimento do espécime ou estágio da flor.

Das espécies de Siphocampylus que ocorrem na região, $S$. sulfureus é a mais diferenciada, tanto em relação ao habitat e hábito, como em seus caracteres morfológicos. A espécie habita brejos de attitude, que aparecem inundados em seu periodo de floração e frutificação. É confirmadamente uma espécie anual, que floresce e frutifica nos meses de dezembro a maio, formando grandes populaçōes. Tais plantas aparecem nos meses de junho a novembro senescentes. Neste 
periodo, pode-se observar também a instalaçāo de plântulas, muitas vezes encobertas por outras espécies de brejo que ai se instalam. A espécie parece ser dependente do ambiente alagado para dispersão e germinação de suas sementes, pois a seqüência ao seu desenvolvimento vegetativo á dada no periodo em que o nível da água diminui muito.

Quanto ao hábito, é erva robusta, ereta, de grandes folhas lanceoladas, com disposição verticilada em entrenós distanciados, assemelhando-se a espécies do gênero Lobelia L., principalmente L. fistulosa Vell., com a qual compartilha as mesmas áreas de brejo. É referida por muitos coletores como "erva fedorenta", pois exala odor desagradável, semelhante ao do lobo guará. Tal odor deve ser o responsável pelo nome vulgar dado à espécie na regiäo de Minas Gerais: "jaratataca" (Corrêa 1984). Este autor a cita sob o nome de $S$. verticillatus. Como essa característica näo ocorre em S. verticillatus, considero que esse nome vulgar é da espécie S. sulfureus. Corrobora a explanação acima, a informação verbal do Guarda do IBDF do Parque da Serra do Cipó, sobre a existência na regiāo de um "cachorrinho" selvagem, denominado "jaratitaca", que ao ser capturado elimina um odor muito desagradável.

Em relação às flores, $S$. sulfureus apresenta a corola menos vistosa e menor que as demais, reta, sulfúrea ou amarelo-pálida. A corola também é distinta das outras espécies do gênero por apresentar quatro lobos iguais e o lobo inferior disjunto até próximo à base, o que a coloca grosseiramente próxima à corola típica do gênero Lobelia, que é totalmente fendida na região anterior.

Outra distinção morfológica diz respeito às sementes, que têm uma característica não observada nas demais espécies de Siphocampylus, que é uma pequena ala que circunda $3 / 4$ do núcleo seminifero.

Apesar de $S$. sulfureus ter tantas caracteristicas que a distinguem das demais espécies do gênero, inúmeras vezes foi identificada como $S$. verticillatus, pois as duas espécies são muito semelhantes em relaçăo ao hábito, diferindo no entanto em relação à corola, que em $S$. verticillatus é semelhante à das demais espécies analisadas no gênero: subcurvada, de lobos quase iguais, vermelha, com ápice dos lobos amarelos.

3. Siphocampylus westinianus (Billb.) Pohl, PI. Brasil. Icones et Descript. 2: 115. 1831.

Figs. 14-16

Nome vulgar: bico-de-papagaio, (fide Oliveira 056, BHCB).

Subarbustos com ramos inferiores glabros e superiores vilosos, 0,70-1,50 m alt. . Caule finamente estriado. Folhas verticiladas, 3 a 4 por verticilo, raro esparsas, aproximadamente opostas, membranáceas, ovais a oval-lanceoladas ou oval-oblongas, $3,0-12,0 \mathrm{~cm}$ compr., $1,8-6,0 \mathrm{~cm}$ larg., de coloração verde-escura na face adaxial e pálida na abaxial; face adaxial pouco brilhante, glabra ou com tricomas curtos, esparsos; face abaxial vilosa com tricomas alvos ou castanhoavermelhados nas nervuras que sāo proeminentes; margem denteado-denticulada, dentículos desiguais, alvos ou castanhos, de ápice proeminente, raro subíntegra; base foliar atenuada, obtusa ou arredondada, até subcordada; ápice agudo a acuminado; peciolo 0,1-1,5 cm compr., viloso. Flores verticiladas, em número igual ao das folhas; pedicelo $0,9-6,0 \mathrm{~cm}$ compr., viloso, bibracteolado na base; corola 4,0 - $5,5 \mathrm{~cm}$, tubo hirto, vermelho, subcurvado, mais ou menos amplo; lobos de base amarela e ápice verde, falcados, desiguais, com cerca de $1 / 4$ do comprimento da corola. Hipanto 0,2 - 0,4 cm compr., 0,4-0,7 cm larg., turbinado, viloso, base aguda; lobos angusto-triangulares, denticulados, $0,3-0,6 \mathrm{~cm}$, eretos, raro subcurvados, vilosos; tubo de filetes glabro ou com tricomas na regiäo superior do tubo, estendendo-se até a base, $0,7-0,9 \mathrm{~cm}$ compr., $0,2 \mathrm{~cm}$ larg. 
Cápsula piriforme, pubescente, $0,7-0,9 \mathrm{~cm}$ compr., $0,6-1,2 \mathrm{~cm}$ larg.; sementes muitas, elipticas, achatadas, reticuladas, castanho-escuras, $0,7 \mathrm{~mm}$.

\section{Chave para as variedades}

1. Folhas subsésseis, verticiladas

a.var. westinianus

1 ' Folhas pecioladas, esparsas, inferiores opostas, superiores tendendo a verticiladas

\section{3.a. S. westinianus (Billb.) Pohl var. westinianus}

b.var. sparsifoliatus

Material selecionado. Santana do Riacho, Serra do Cipó, Rodovia Belo Horizonte-Conceição do Mato Dentro: km 126, CFSC 9947, col. S.A.P. Godoy \& N.S. Chukr, 16.l.1987 (SPF); km 128, CFSC 10886, col. S.A.P. Godoy, J.M. Piliackas \& V. Piliackas, 14.11.1988 (SPF); km 129, CFSC 9944, col. S.A.P. Godoy \& N.S. Chukr, 16.1 .1987 (SPF); km 131, CFSC 9479, col. N.L. de Menezes et al., 14.XII.1985 (SPF); km 132, CFSC 9143, col. M.L. Kawasaki, M.G.M. Arraes, M. Venturelli, 05.XI.1983 (SPF); km 134, col. T.M. Cerati et al. 93, 07.l.1984 (SP); km 135, CFSC 10882, col. S.A.P. Godoy, J.M. Piliackas \& V. Piliackas, 14.11 .1988 (SPF); km 140, col. A. Furlan \& M. das G. Sajo, 29.ll.1980 (SP 185397); km 141, col. Mello Barreto, 24.VIII.1933 (R 98684); km 142, col. J. Semir, D.A. Lima, 15.XII.1973 (SP 145745).

3.b. S. westinianus (Billb.) Pohl var. sparsifoliatus E. Wimm., Revista Sudamer. 2: 98. 1935.

Material examinado. Santana do Riacho, Serra do Cipó, Rodovia Belo Horizonte-Conceição do Mato Dentro: km 128, CFSC 10887, col. S.A.P. Godoy, J.M. Piliackas \& V. Piliackas, 14.1l.1988; km 135, CFSC 10373-A, col. S.A.P. Godoy, A. Salatino \& M.L.F. Salatino, 22.VIl.1987 (SPF); km 138, CFSC 10818, col. S.A.P. Godoy et al., 13.Xll.1987 (SPF).

S. westinianus é espécie do Brasil, principalmente distribuida nos estados de Minas Gerais, Rio de Janeiro, São Paulo e Goiás, em regiōes serranas, que variam de $1000-1600 \mathrm{~m}$ de altitude. Predomina em campos rupestres úmidos, podendo ser encontrada em orlas de mata, raro em áreas de cerrado. A maior incidência de espécimes floridos encontra-se nos meses de dezembro a julho.

S. westinianus (Billb.) Pohl apresenta ampla variação, em relação à forma, dimensão e disposiçã̀o das folhas, ao número de folhas por verticilo, ao tamanho da corola, do peciolo e pedicelo, bem como à distribuição de tricomas. Tal variação permitiu a Wimmer (1957) subdividir a espécie em quatro variedades e uma forma. Das variedades estabelecidas por Wimmer, na Serra do Cipó foi possivel considerar como válida a var. sparsifoliatus, cuja distribuição de folhas no ramoé esparsa, sendo que as inferiores são nitidamente opostas, tendendo a regiāo superior do ramo apresentar folhas verticiladas.

Quanto às demais variedades, o material examinado, permitiu observar que as características utilizadas pelo autor como diagnósticas das mesmas, podem aparecer no grupo segundo vários estados, inclusive num mesmo espécime. A relaçāo entre o tamanho do pedicelo e o tamanho da folha é extremamente dependente do desenvolvimento do espécime analisado e da altura do ramo coletado, sendo que as folhas inferiores são sempre maiores que as superiores e nem sempre estão à disposição, visto que muitas coletas apresentam como exsicatas só o ramo com flores. O tamanho do pedicelo também acompanha o desenvolvimento da flor, desde o estágio de botāo até $o$ de fruto. A forma da folha pode ser um tanto variável no mesmo espécime, o que dificulta a 
distinçāo na transição gradual de oval-lanceolada a oval-ọblonga. Outra característica utilizada por Wimmer para distinguir as variedades é a presença de tricomas no tubo de anteras; tal característica além de apresentar transição gradual, sendo em alguns casos evidente no botão ou flores jovens e de dificil visualizaçāo nas flores mais velhas, não é particular de nenhuma população, não sendo possivel, como propōe o autor, estabelecer a var. kanitzii por tal caracteristica. S. westinianus apresenta, portanto, inúmeras dificuldades de classificação infraespecífica, e como os espécimes são homogêneos em sua preferência ecológica, năo há como relacionar a variação a mudanças ambientais, exceto para a var. sparsifoliatus, cujos exemplares observados são sempre de orla ou até mesmo interior de matas ciliares; contudo, como mencionado acima, tais espécimes, quando coletados e herborizados criteriosamente, chamam logo a atenção por possuírem folhas dispostas irregularmente na regiăo inferior, passando gradativamente à filotaxia verticilada em direção ao ápice.

Quanto à biologia floral, há citaçōes de campo sobre a visita de beija-flores (col. T.M.S. Grandi \& Tales 102, 01.V.1980 - BCHB).

\section{LobeliaL.}

Ervas latescentes, pequenas ou robustas, anuais, bianuais ou perenes; caule fistuloso ou não, cilíndrico ou anguloso, simples ou ramificado, glabro ou pubescente. Folhas simples, alternas, sésseis ou curto-pecioladas, margem inteira ou com dentículos, adpressos ou não, serreada ou denteada com dentes de ápice proeminente, glabras ou pubescentes. Flores isoladas axilares ou em inflorescências racemosas terminais, ressupinadas; brácteas 2, deflexas ou eretas, concrescidas ou nāo na base do pedicelo ou ausentes; pedicelo ereto ou deflexo até arcado-sigmóide, cilindrico ou anguloso; corola zigomorfa, geralmente bilabiada, sendo 2 lobos superiores aproximadamente eretos, disjuntos até a base, separados por fenda anterior e 3 inferiores, deflexos, ligados até $2 / 3$ do seu comprimento. Hipanto obcônico, ápice agudo a obtuso, lobos 5 , iguais, margem inteira, serreada ou denticulada; estames 5; filetes livres da corola, unidos em tubo até próximo à base ou disjuntos até $2 / 3$ de seu comprimento, anteras basifixas, ligadas lateralmente em tubo levemente curvado, introrsas, desiguais, 2 inferiores menores, as 2 inferiores ou todas piloso-peniceladas; ovário infero, bilocular, muitos óvulos, placentação axial; estigma bilobado, lobos divergentes, superficie estigmática glandular. Cápsula, podendo estar parcialmente livre do hipanto, deiscência apical, sépalas persistentes, raro corola e androceu persistem; sementes muitas, pequenas, orbiculares, elipticas, trigonas ou lenticulares, freqüentemente aladas.

\section{Chave para as espécies}

1. Ervas eretas, até $1,0 \mathrm{~m}$ alt., caule anguloso, compacto

1'Ervas robustas, $2.0-4,5 \mathrm{~m}$ alt., paquicaules, freqüentemente fistulosas.

2. Pedicelo ereto; brácteas eretas, oval-lanceoladas.

2'Pedicelo sigmóide; brácteas deflexas, lanceoladas..

1. L. camporum

1. Lobelia camporum Pohl, Plant. Brasil. Icones et Descript. 2: 100. 1831.

Figs. 20-28

Nome vulgar: voadeira-do-brejo (Corrêa 1984).

Ervas eretas, 0,30-1,0 $\mathrm{m}$ alt., latescentes, algumas rizomatosas; caule anguloso, estriado, glabro ou pubescente. Folhas sésseis, eretas, glabras, ciliadas ou pubescentes com tricomas eriçados na nervura principal; lineares a lanceoladas, podendo as basais formar rosetas de folhas 
oblongas a espatuladas; as inferiores $3,0-15,3 \mathrm{~cm}$ compr., $0,1-1,0 \mathrm{~cm}$ larg.; $\theta$ as superiores 1,0 2,5 cm compr., 0,08 - 0,35 cm larg.; ápice agudo a acuminado; margem denteada, dentículos de ápice proeminente, castanhos ou arroxeados ; base decurrente. Inflorescência em racemo laxo, 2 - 50 flores, raro ramificado; eixo glabro ou pubescente; bráctea $0,3-1,6 \mathrm{~cm}$ compr., $0,1-0,9 \mathrm{~cm}$ larg., séssil, lanceolada, ápice agudo; margem denticulada, pouco pubérula a pubescente. Pedicelo 0,1-0,4 cm compr., bibracteolado, pouco pubérulo a pubescente; corola 0,5-1,7 cm compr., alva ou rosa-pálido, com lobos levemente arroxeados; lilás até roxa; lobo central $0,2-0,9 \mathrm{~cm}$; lobos laterais $0,5-1,7 \mathrm{~cm}$; pubescente interna e externamente, raro glabra externamente. Hipanto obcônico, ápice agudo, hito, 0,15-0,4 cm larg., 0,1 - 0,6 cm compr.; lobos estreito-triangulares, inteiros ou denticulados, glabros ou pouco ciliados, $0,2-0,5 \mathrm{~cm}$; filetes em tubo glabro, pubescentes à altura da disjunçāo até a base, $0,3-0,8 \mathrm{~cm}$ compr.; tubo de anteras albo-viloso, $0,1-0,45 \mathrm{~cm}$ compr., $0,07-0,15 \mathrm{~cm}$ larg. . Fruto ovóide, 0,2-1,3 cm; sementes de duas formas : cilíndricas, reta ou subcurvada; ápices pouco alados, reticulada, $0,08 \mathrm{~cm}$; ou elíptica reticulada, $0,1 \mathrm{~cm}$.

Material selecionado. Santana do Riacho, Serra do Cipó, Rodovia Belo Horizonte-Conceiçāo do Mato Dentro: km 114, CFSC 7016, col. S. Mayo, M.C.E. Amaral \& I. Cordeiro, 28.1l.1981 (SPF); km 126, col. A.B. Joly et al., 05.Ill.1972 ( SP 145859); km 128, CFSC 9934, 9935, 9936, 9941, col. S.A.P. Godoy \& N.S. Chukr, 15.I.1987 (SPF); CFSC 10066, col. V.C. Souza, 13.IV.1987 (SPF); CFSC 10830, col. A. Salatino et al., 13.XII.1987 (SPF); CFSC 10831, col. M.L.F. Salatino et al., 13.12.1987 (SPF); CFSC 10896, col. S.A.P. Godoy, J.M. Piliackas \& V. Piliackas, 15.1l.1988 (SPF); CFSC 10897, col. S.A.P. Godoy, V. Piliackas \& J.M. Piliackas, 15.ll.1988 (SPF); col. M.C. Henrique, M.G. Sajo \& N.M. Castro, 10.1.1981 (SP 2093766); km 131, CFSC 9951, col. S.A.P. Godoy \& N.S. Chukr, 16.I.1987 (SPF); km 139, CFSC 1934, col. S.M.B. Pereira, F.R. Martins \& A.M. Joly, 17.IV.1972 (SPF).

Espécie, no Brasil, distribuida principalmente nos estados de Minas Gerais, Espírito Santo, Rio de Janeiro, São Paulo, Paraná, Santa Catarina, Rio Grande do Sul, Goiás e Distrito Federal; é também citada para a Argentina. Pode ser encontrada em campos de altitude, brejos ou locais onde houve açāo antrópica. A maior concentraçāo de espécimes em flor é no período de dezembro a fevereiro.

Lobelia camporum Pohl apresenta ampla variação entre os espécimes analisados, desde o hábito até a coloração da corola. Devido às variaçōes morfológicas, Wimmer (1957) subdividiu a espécie em duas variedades e uma forma : var. camporum, correspondente ao material tipo proposto por Pohl (1831) e var. Iundiana, com menor grau de pilosidade e maior tamanho das brácteas. Para esta variedade, admitiu ainda a forma angustifolia, distinta pelas brácteas e folhas muito reduzidas. Posteriormente foram descritas como espécies novas, L. paranaensis (Braga 1956) e L. paulista (Wimmer 1968). Vieira (1988) sinonimiza os binômios citados a L. camporum, concluindo apös extenso estudo sobre a espécie, a nivel de análise citológica, análise em MEV das células da testa das sementes $\Theta$ análises fenéticas para as características que apresentavam variação, tratar-se de um complexo poliplóide, tendo detectado um diplóide e dois hexaplóides, com números cromossômicos $n=7$ en=21, respectivamente, permitindo-lhe estabelecer dois padrōes, que denominou como agrupamento le II, designando para o primeiro plantas menores quanto à altura, folhas, brácteas e corola, que é de cor lilás, arroxeada ou azul, $n=7$, sementes cilindricas ou elipticas; mais freqüentes em brejos e para o segundo plantas maiores, corola alva ou rósea, com lobos levemente lilases, sementes cilindricas, $n=21$; que ocupam principalmente locais úmidos ou mais secos de regiōes perturbadas pelo homem ou em transiçāo de vegetaçāo. 
Na região encontrou-se representantes morfologicamente afins aos padrōes estabelecidos por Vieira (1988) e representantes intermediários, como é o caso dos espécimes CFSC 9935, CFSC 9951 e CFSC 10830, cujas caracteristicas morfológicas e o habitat assemelham-se aos dois agrupamentos. Conclui-se portanto, manter a sinonimia estabelecida por Vieira (1988), não sendo possivel, pelas características observadas, estabelecer taxa infraespecificos.

2. Lobelia fistulosa Vell., Fl. Flum.(texto) p. 353. 1829.; Flora Fluminensis (lcones) t. 157. 1835.

Figs. $35-39$

Nome vulgar: piuninha-do-brejo [fide Sampaio 498(R); Corrêa (1984)].

Erva fistulosa, 2,0 - 4,5 m alt.; látex abundante, branco; caule cilíndrico, estriado, fistuloso, cerca de $3 \mathrm{~cm}$ de diâmetro, glabro ou pubescente. Folhas linear-lanceoladas, lanceoladas até oblongas, glabras, discolores, face adaxial verde-escura ou acastanhada, face abaxial verde-clara; cartáceas, 16,0-53,0 cm compr., 1,0-5,7 cm larg; margem inteira, com dentículos irregulares, adpressos ou nāo, ápice proeminente, alvos ou castanho-arroxeados, ciliados; base atenuada. subdecurrente; nervura principal tornando-se caniculada em direção à base. Inflorescência racemosa, terminal, até 1,0 $\mathrm{m}$ alt., raro ramificada na base; bráctea, 2,4-4,4 cm compr., 0,7 - 2,5 cm larg., ereta; oval-lanceolada, verde a verde-vinácea, glabra, ápice subacuminado a acuminado até agudo; margem inteira com dentículos de ápice proeminente, alvos ou castanho-arroxeados, ciliados; base decurrente unida ao pedicelo, que é achatado, levemente estriado, ereto, geralmenie sem. bractéolas, hirsuto, $0,6-2,5 \mathrm{~cm}$ compr.,; corola sulferina, hirsuta interna e externamente, 3,8 - 5,0 cm compr.; lobos superiores $1,1-2,0 \mathrm{~cm}$ compr. e inferiores $0,3-0,8 \mathrm{~cm}$ compr. . Hipanto largorurbinado, verde a verde-vináceo, $0,3-1,2 \mathrm{~cm}$ larg., $0,15-0,5 \mathrm{~cm}$ compr., hirsuto; lobos triângulolanceolados, ápice acuminado, verdes a verde-vináceos, ciliados próximo à base, pubescentes, margem inteira, denticulada; filete pubescente, $3,2-4,0 \mathrm{~cm}$ compr.; tubo de anteras cinéreo, 0,8 $1,0 \mathrm{~cm}$ compr., $0,2 \mathrm{~cm}$ larg., com tricomas esparsos. Fruto ovóide a globoso, livre mais de $2 / 3$ do total, $0,6-1,9 \mathrm{~cm}$ larg., $0,8-1,8 \mathrm{~cm}$ compr.; sementes muitas, orbiculares, amplo-aladas, $0,1-0,17$ $\mathrm{cm}$.

Material examinado. Santana do Riacho, Serra do Cipó, Rodovia Belo Horizonte-Conceiçăo do Mato Dentro: Alto do Palácio, CFSC 10781, col. S.A.P. Godoy, F.R.S. Pires \& V. Abbud, 09.X.1987 (SPF); CFSC 10835, col. S.A.P. Godoy et al., 13.XIl.1987 (SPF); CFSC 10836, col. S.A.P. Godoy et al., 13.XIl.1987 (SPF); CFSC 10894, col. S.A.P. Godoy, J.M. Piliackas \& V. Piliackas, 15.11 .1988 (SPF); km 129, col. A.B. Joly, A.M. Giulietti, N.L. de Menezes \& P. Windisch, 20.X.1973 (SP 145846); Córrego do Vitalino, col. I. Cordeiro, J.R. Pirani \& A. Furlan, 16.XII.1980 (SP 185407); km 135, col. H.S. Irwin, H. Maxell \& D.C. Wasshausen, 19.ll.1968 (NY 20544); km 140, col. G. Hatschbach 28873, 18.1.1972 (MBM); km 142, col. Mello Barreto 8833, 03.1l.1938 (R).

Espécie do Brasil, ocorre nos estados de Minas Gerais, Rio de Janeiro e São Paulo. Muito freqüente em brejos ou locais alagadiços nas épocas chuvosas. Há referências para locais úmidos em matas, cerrados ou ambientes secos $€$ abertos como campos e locais revolvidos pelo homem, como as margens de estradas (Vieira 1988). Floresce de outubro a fevereiro, com o pico de floração em janeiro e fevereiro.

Morfologicamente, L. fistulosa Vell., apresenta a menor variaçāo entre os espécimes se comparada a outras espécies do gênero, nāo sendo de difícil identificaçäo. 
É citada como enva anual (Vieira 1988), com rebrota próxima à base ou no ápice, após quebra, originando plântulas que desprendem-se da planta mãe senescente para formar novos individuos; esta forma de crescimento já foi mencionada por Mabberley (1974) para espécies africanas. No entanto, por observaçōes na populaçāo da Serra do Cipó (Km 128), a espécie é bianual, vegetando no primeiro ano e desenvolvendo flores e frutos no segundo, após o que senesce. Quanto à rebrota, este fenômeno nāo foi observado, o que nāo invalida a afirmação acima, pois a população muito se assemelha à citação de Coe (1967 apud Mabberley 1974), segundo o qual tal hábito leva à formação de "family groups".

L. fistulosa é facilmente distinguida das demais espécies de Lobelia "paquicaules" brasileiras pela posição e forma das bractéas e pelas sementes de ala maior.

3. Lobelia organensis Gardner, Hook. Lond. Journ. Bot. 4: 128. 1845.

Figs. 29-34

Nome vulgar: vela-da-pureza (na Bahia, fide Pinheiro s. n., CEPEC).

Erva fistulosa, 2,0 - 3,8 m alt.; látex amarelado; caule cilindrico, estriado, fistuloso, glabro ou com tricomas esparsos. Folha amplo-lanceolada a estreito-lanceolada, cartácea, glabra verdes ou discolores com a face adaxial verde-acastanhada $\theta$ a face abaxial verde-amarelada, 17,0 - 35,0 cm compr., 2,2 - 5,0 cm larg.; ápice agudo ou acuminado; margem inteira a pouco denteada, denticulada, dentículos desiguais, adpressos ou não, de ápice proeminente alvo ou castanho-escuro, ciliados ou não, mais freqüentemente ciliada na base; base atenuada, decurrente, às vezes formando pequena ala; a nervura principal torna-se caniculada em direçāo à base. Inflorescência racemosa, terminal, até $1,5 \mathrm{~m}$, com inflorescências secundárias na base do eixo, que é glabro ou pubérulo, profundamente estriado, verde ou verde-arroxeado. Bráctea, 1,5-5,0 cm compr., 0,15-0,9 $\mathrm{cm}$ larg., lanceolada, deflexa, glabra, raro pubérula; margem inteira, ciliada; base decurrente, concrescida ao pedicelo. Pedicelo, 1,3-2,5 cm compr., cilindrico, sigmóide-ascendente, ciliado na base ou não, glabro, raramente pubérulo, ebracteolado. Corola, $3,5-4,0 \mathrm{~cm}$ compr., violácea, glabra, lobos superiores $1,5-3,0 \mathrm{~cm}$, lobos inferiores $0,35-1,5 \mathrm{~cm}$ compr. . Hipanto, 0,6 $-1,3 \mathrm{~cm}$ larg., 0,2-0,5 cm compr., curto, semigloboso; nervaçāo pouco evidente, glabro ou pubérulo; lobos triângulo-lanceolados, 1,3-1,9 cm compr., glabro ou pubérulo, ápice agudissimo, margem inteira; filete pubescente, $2,5-3,2 \mathrm{~cm}$; tubo de anteras $0,8-1,2 \mathrm{~cm}$ compr., $0,2 \mathrm{~cm}$ larg., com tricomas esparsos ou glabro. Fruto ovóide, de 1/3 a mais que $2 / 3$ livres, $0,8-1,3$ larg., 1,0 - 1,8 cm compr., semente lenticular, suborbiculada, amplo-alada, 0,1-0,15 cm larg. .

Material examinado. Santana do Riacho, Serra do Cipó, Rodovia Belo Horizonte-Conceição do Mato Dentro; Fazenda Palácio, col. G. Hatschbach 22443, 08.VIII.1972 (MBM); km 129, col. A.M. Giulietti, 08.VII.1973 (SP 145848); km 137, CFSC 7328, col. A.M. Giulietti et al., 30.VI.1981

Figs. $20-39$ - Labelia : $20-24$ - L. camporum Pohl, padrão ll, 20 - Hábito, 21 - Flor, corte longitudinal, 22 Bráctea, 23-24 - Semente. 25-28 - L. camporum Pohl, padrăo I, 25 - Hábito, 26 - Flor em vista lateral, 27 Bráctea, 28 - Semente. 29-34 - L. organensis Gardn., 29 - Seccào do ramo e parte da inflorescéncia, 30 -

Folha, apice, face abaxial, 31 - Flor, em vista lateral com bráctea, 32 - Base da flor, corte longitudinal, 33 - Fruto imaturo, 34 - Semente. 35-39 - L. fistulosa Vell., 35 - Inflorescéncia, 36 - Flor em vista lateral, 37 - Bractea e
parte do pedicelo, 38 - Flor, corte longitudinal, 39 - Semente.

Figs. 20-39 - Lobelia:20-24 - L. camporum Pohl, group II, 20 - Habit, 21 - Flower, longitudinal section, 22 Bract, 23-24 - Seed. 25-28 - L. camporum Pohl, group 1, 25 - Habit, 26 - Flower, lateral view, 27 - Bract, 28 Seed. $29-34$ - L. organensis Gardn., 29 - Section of shoot and part of infiorescence, 30 - Leaf, apex, abaxial face, 31 - Flower, lateral view, with bract, 32 - Base of flower, longitudinal section, 33 - Immature fruit, 34 - Seed 35-39 - L fistulosa Vell., 35 - Inflorescence, 36 - Flower, lateral view, 37 - Bract and part of pedicel, 38 - Flower, longitudinal section, 39 - Seed. 


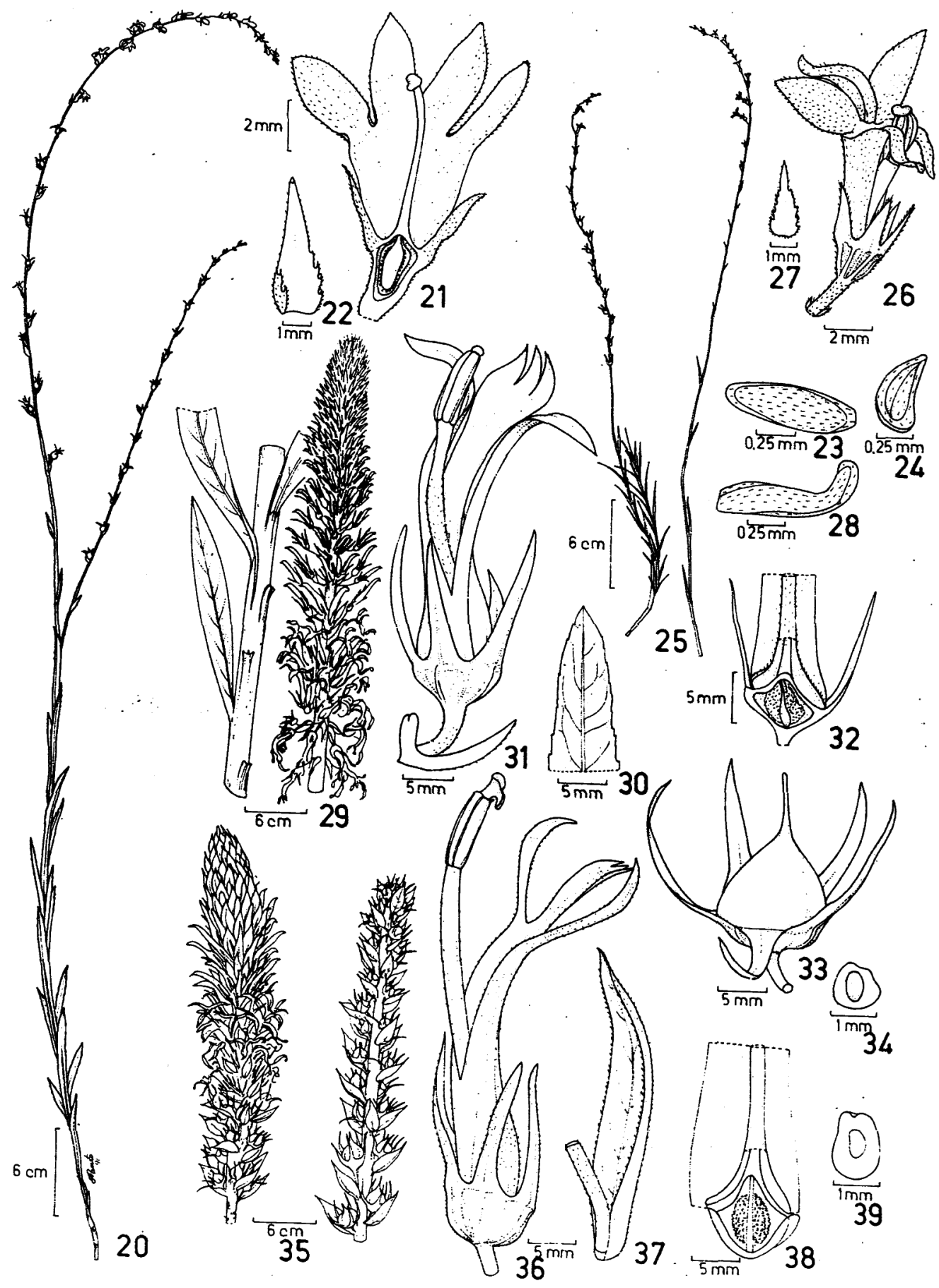


(SPF); km 137,5, col. A.B. Joly J. Semir \& Y. Ugadim, 08.VI.1970 (SP 145852); km 139, CFSC 11150, col. S.A.P. Godoy ot al., 25.VI.1988 (SPF); km 142, CFSC 9917, col. S.A.P. Godoy et al., 12.X.1986 (SPF); CFSC 10369, col. S.A.P. Godoy, A. Salatino \& M.L.F. Salatino, 22.VII.1987 (SPF); CFSC 10374, col. S.A.P. Godoy, A. Salatino, M.L.F. Salatino, 22.VII.1987 (SPF); CFSC 11144, col. S.A.P. Godoy et al., 25.VI.1988 (SPF); col. A.B. Joly, J. Semir, 22. VIll.1972 (SP 145841); col. A.B. Joly et al., 27.V.1972 (SP.145844); col. A.P. Duarte 5122, 16.IX.1950 (RB); CFSC 1191, col. A.B. Joly, J. Semir, 22.VIII.1972 (UEC); s/km, col. M. Magalhães 18063, VIII.1960 (IAN).

Vieira (1988) reconhece para a L. organensis três subspécies, organensis, kanitzii (E. Wimm.) A.O.S. Vieira $\theta$ brasiliensis A.O.S. Vieira, diferenciando-as pelo tipo de indumento, dimensōes de folhas, dimensōes e coloração de corolas, bem como a distribuição geográfica. As duas primeiras subspécies sāo similares quanto à distribuiçāo geográfica e morfologia $\theta$ a principal diferença reside no indumento conspícuo das folhas de kanitzii e corola maior. A subspécie brasiliensis apresenta as menores dimensōes para folhas e corola do grupo, bem como indumento conspicuo, amarelado, em diferentes estruturas florais e folhas e é restrita ao Distrito Federal-GO. $\mathrm{Na}$ Serra do Cipó, encontrou-se apenas espécimes que se enquadram em L. organensis ssp. organensis, de corola menor, arroxeada, com folhas glabras. Esta subespécie ocorre nos estados da Bahia, Minas Gerais, Espirito Santo e Rio de Janeiro. Ocupa locais abertos, pedregosos, em orla de matas de galeria, próximos a rios ou riachos ou locais brejosos, até mesmo em locais devastados, como beira de estradas, em altitudes acima de $1200 \mathrm{~m}$. Espécimes em flor são encontrados especialmente em julho, agosto e setembro.

L. organensis ssp. organensis pode ser distinta das demais espécies de Lobelia "paquicaules" pela semente, cuja ala é ampla, o que a diferencia de L. thapsoidea Schott. e L. langeana Dusén, embora a assemelhe a L. fistulosa Vell. e L. exaltata Pohl, podendo ser separada da primeira pela posição e forma das brácteas e da segunda pelo tamanho e coloração das flores.

Quanto à biologia floral, em observaçōes de campo, suas flores são constantemente visitadas por beija-flores.

Agradecimentos - À Profa. Dra. Ana Maria Giulietti, pela revisão do estudo taxonômico e pelas discussōes que auxiliaram o desenvolvimento da Dissertação de Mestrado, que possibilitou essa publicaçāo. Ao Prof. Renato de Mello-Silva, pelo auxílio e sugestōes na montagem do trabaIho ora publicado.

\section{REFERENCIAS}

BARROSO, G.M., PEIXOTO, A.L., COSTA, C.G., ICHASO, C.L.F. GUIMARÃES, E.F.\& LIMA, H.C. de. 1986. Sistemática de Angiospemas do Brasil. Vol. 3. Imprensa Universitária. Viçosa.

BRAGA, R.E. 1956. Lobélias do Brasil; contribuição para o seu estudo. Arq. Biol. Tecnol. 11(5): 27-94.

CORREA A. M.P. 1984. Dicionkirio das Plantas úteis do Brasil e das Exóticas cultivadas. Vol. 2, 4 e 6. Imprensa Nacional. Rio de Janeiro.

CRONQUIST, A. 1981. An integrated System of Classification of Flowering Plants. Columbia Univ. Press. New York.

GIULIETT1, A.M., MENEZES, NL., PIRANI, J.R., MEGURO, M. \& WANDERLEY, M.G.L. 1987. Flora da Serra do Cipó, Minas Gerais: caracterização e lista das espécies. Bolm Botánica, Univ. S. Pauilo 9: 1-151.

GODOY, S.A.P. de. 1989. Levantanento Florístico e Quimiossitemático da Fantilia Canpanulaceae - Região da Cadeia do Espinhaço. Dissertação de Mestrado. Instituto de Biociências, Universidade de São Paulo.

KANITZ, A. 1885. Lobeliaceae; Campanulaceae. In C.F. Martius \& A.G. Eichler (eds.). Fl. Bras. 6(4): 131-158; $179-186$.

MABBERLEY, D.J. 1974. The Pachycaul Lobelias of Africa and St. Helena. Kew Bull. 29(3): 535-584.

POHL, J.E. 1831. Plantarum Brasiliae Icones et Descriptiones Hactenus Ineditae. 2: 100-115.

THULIN, M. 1975. The genus Wahlenbergia s. lat. (Campanulaceae) in Tropical Africa and Madagascar. Almqvist \& Wiksell International. Sweden. 
VDIIRA, A.O.S. 1988. Estudos Taronômicus das Espécies de Lobelia L (Campanulaceae Juss.) que ocorrem no Brasil. Dissertação de Mestrado. Instituto de Biologia. Universidade Estadual de Campinas.

WIMMER, E.F. 1957. Campanulaceae-Lobelioideae. In A. Engler(ed.) Dás Pflanzenreich. IV. 276 b.: V.I.

WIMMER, E.F. 1968. Campanulaceae-Lobelioideae. Supplementum et Canpanulaceae-Cyphioideae. In A. Engler (ed.) Das Pflauzenreich. IV. 276 c.: $815-2014$. 